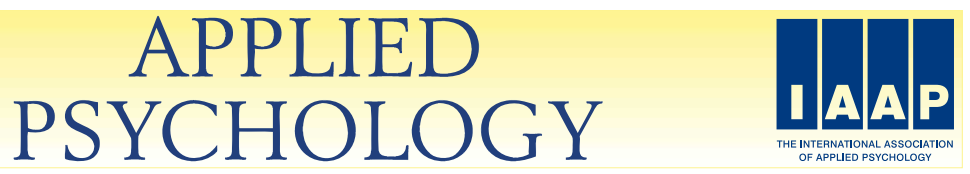

APPLIED PSYCHOLOGY: AN INTERNATIONAL REVIEW, 2012, 61 (1), 30-55 doi: $10.1111 /$ j.1464-0597.2011.00454.x

\title{
For Fun, Love, or Money: What Drives Workaholic, Engaged, and Burned-Out Employees at Work?
}

\author{
Ilona van Beek* \\ Utrecht University, The Netherlands
}

Qiao $\mathrm{Hu}$

Yongkang Nursing School of Zhejiang Province, China

\author{
Wilmar B. Schaufeli and Toon W. Taris \\ Utrecht University, The Netherlands
}

\author{
Bert H.J. Schreurs \\ Maastricht University, The Netherlands
}

\begin{abstract}
Previous research has distinguished between two types of working hard: workaholism, a "bad" type of working hard, and work engagement, a "good" type of working hard. However, the motivations underlying workaholism and work engagement have not been examined extensively. Building on Deci and Ryan's Self-Determination Theory, the present study examined the motivational correlates of workaholism, work engagement, and burnout (a possible consequence of working hard), using data from Chinese health care professionals (544 nurses and 216 physicians), and controlling for job demands and resources. As expected, structural equation modeling revealed that high levels of workaholism were associated with high levels of introjected regulation and identified regulation; that high levels of work engagement were mainly associated with high levels of intrinsic regulation; and that high levels of burnout were mainly associated with low levels of intrinsic regulation. Thus, different types of motivational regulation are associated with different types of jobrelated well-being.
\end{abstract}

\footnotetext{
* Address for correspondence: I. van Beek, Utrecht University, Department of Work and Organizational Psychology, P.O. Box 80.140, NL-3508 TC Utrecht, The Netherlands. Email: I.vanBeek@uu.nl
} 


\section{INTRODUCTION}

The world of work is rapidly changing. Global competition, the high pace of innovation, and the tendency towards assigning people to projects rather than to jobs make work more demanding (Frese, 2008). In response to these developments, employees must continuously expand their knowledge, build social networks, and compete with others. Moreover, with the advent of the internet and computer-based working, employees can work wherever and whenever they want, blurring the boundary between work and private life. Taken together, these changes both allow and stimulate employees to work harder than before.

Two types of working hard can be distinguished: workaholism, a "bad" type, and work engagement, a "good" type (Shimazu \& Schaufeli, 2009). Since these two forms of working hard are associated with different individual and organisational outcomes (Schaufeli, Taris, \& Van Rhenen, 2008), it is vitally important to enhance our understanding of the relation between working hard and work motivation. The present study addresses this issue by examining workaholism, work engagement, and burnout in relation to the qualitatively different types of motivation described in Deci and Ryan's (1985) Self-Determination Theory.

\section{Workaholism, Work Engagement, and Burnout}

Workaholism, work engagement, and burnout are three different kinds of job-related well-being (Schaufeli et al., 2008). Workaholism refers to "the tendency to work excessively hard and being obsessed with work, which manifests itself in working compulsively" (Schaufeli, Shimazu, \& Taris, 2009c, p. 322). Workaholic employees work harder than their colleagues and harder than is required in order to meet organisational or economic standards. They think about their work continuously and they experience a strong and uncontrollable inner drive to work hard (McMillan \& O'Driscoll, 2006; Scott, Moore, \& Miceli, 1997). In this sense, workaholic employees are driven or "pushed" to work.

Workaholism is related to a variety of negative outcomes for employees, their spouses, and their companies. For instance, workaholic employees experience more interpersonal conflict at work (Mudrack, 2006), are less satisfied with their jobs (Burke \& MacDermid, 1999), report more workhome interference (Schaufeli, Bakker, Van der Heijden, \& Prins, 2009a; Taris, Schaufeli, \& Verhoeven, 2005), and have poorer social relationships outside work than other employees (Bonebright, Clay, \& Ankenmann, 2000). Further, they experience low life satisfaction (Bonebright et al., 2000; McMillan \& O'Driscoll, 2004) and high levels of job strain and health complaints (Burke, 2000). Judging from these negative outcomes, workaholism clearly is a bad type of working hard.

(C) 2011 The Authors. Applied Psychology: An International Review (C) 2011 International Association of Applied Psychology. 
Work engagement is a positive, fulfilling, work-related state of mind that is characterised by vigor, dedication, and absorption (Schaufeli, Salanova, Gonzalez-Romá, \& Bakker, 2002). Vigor refers to high levels of persistence, energy, and mental resilience while working, and the willingness to invest effort in one's work. Dedication refers to being strongly involved in one's work, and experiencing a sense of significance, enthusiasm, inspiration, pride, and challenge. Finally, absorption refers to being fully concentrated and deeply engrossed in one's work, whereby time passes quickly and one has difficulties with detaching oneself from work. Therefore, engaged employees are characterised by passion for their work (Schaufeli \& Bakker, 2010): They are "pulled" to work.

Unlike workaholism, work engagement is associated with positive outcomes. Engaged employees are more satisfied with their jobs and are more committed to the organisation (Schaufeli et al., 2008), show more proactivity (Salanova \& Schaufeli, 2008; Sonnentag, 2003), and exhibit more extra-role behavior and perform better (Salanova, Agut, \& Peiró, 2005). Moreover, they experience high life satisfaction and good health (Schaufeli \& Salanova, 2007a; Schaufeli et al., 2008). Therefore, work engagement is a good type of working hard.

Burnout is often defined as a state of exhaustion in which workers are cynical about the value of their occupation and doubtful of their capacity to perform (Maslach, Jackson, \& Leiter, 1996). The core of burnout consists of exhaustion (i.e. the depletion of mental resources) and cynicism (an indifferent and detached attitude toward one's job). The third aspect of burnout, lack of professional efficacy, is currently not considered a central aspect of burnout (Schaufeli \& Salanova, 2007b) and is not examined here. In contrast to workaholic and engaged employees, employees experiencing burnout are not pushed or pulled to work. Rather, they have developed a mental distance towards their work.

Like workaholism, burnout is related to a variety of negative outcomes. Employees experiencing burnout are more dissatisfied with their jobs, are less committed to the organisation, are more often planning to leave the organisation, are more often absent, and perform poorer than other employees (Maslach, Schaufeli, \& Leiter, 2001). Moreover, burnout is related to health complaints such as depression, psychosomatic complaints, cardiovascular diseases, sleep disturbances, anxiety, and acute infections (Shirom, Melamed, Toker, Berliner, \& Shapira, 2005). Consequently, burnout is a detrimental job-related state of mind.

Although the conceptualisation of workaholism, work engagement, and burnout and their consequences have been studied in detail, their motivational antecedents have hardly been examined. This is especially salient because it is likely that these antecedents differ. The present study fills this gap using Deci and Ryan's (1985) Self-Determination Theory (SDT).

(C) 2011 The Authors. Applied Psychology: An International Review (C) 2011 International Association of Applied Psychology. 


\section{Self-Determination Theory}

According to SDT, human beings are active, growth-oriented organisms: They are predisposed to engage in interesting and enjoyable activities, to use their capacities fully, to search for connectedness with others, and to integrate their experiences (both intrapersonal and interpersonal) in a relative unity (Deci \& Ryan, 2000). SDT proposes that the social environment influences the growth-oriented tendency by either supporting or thwarting it. Therefore, the interaction between individuals and their environment is the basis for predictions about motivation, behavior, and the extent to which personal growth takes place.

Within SDT, a major distinction in the motivational regulation of behavior is made between intrinsic and extrinsic motivation. Individuals who are intrinsically motivated to perform an activity experience that activity as interesting, enjoyable, and satisfying, that is, they engage in an activity for its own sake and act with a full sense of volition (Gagné \& Deci, 2005; Ryan \& Deci, 2000a). Therefore, intrinsically motivated behavior is autonomous or selfdetermined. Individuals who are extrinsically motivated to perform an activity do so because of its instrumental value (Gagné \& Deci, 2005; Ryan \& Deci, 2000b). For them, the outcome of the activity differs from the activity itself. For instance, most work behavior will be partly externally motivated as work is not exclusively interesting, enjoyable, and satisfying. Most individuals work to earn a living and must therefore accept that work is not just fun.

SDT proposes that extrinsic motivation varies regarding the extent to which behavior is autonomous or self-determined (Ryan \& Deci, 2000a). First, two types of controlled extrinsic motivation are distinguished: external and introjected regulation. Externally regulated behavior is motivated by external contingencies involving threats of punishments, and material or social rewards. For example, an employee whose work behavior is externally regulated may perform his work to avoid being criticised by his supervisor or to obtain a salary increase. This type of behavior is experienced as most controlled, since it is regulated by the social environment and, thus, non-selfdetermined. Introjected regulation is a product of an internalisation process in which individuals rigidly adopt external standards of self-worth and social approval without fully identifying with them. Meeting these introjected standards results in feelings of self-worth and self-esteem, whereas failing to meet these standards leads to self-criticism and negative feelings (Deci \& Ryan, 2002; Koestner \& Losier, 2002). Thus, introjected regulation represents regulation by contingent self-esteem (Ryan \& Deci, 2000b). For example, an employee who is motivated by introjected regulation does her work in order to obtain positive feelings such as pride or to avoid negative feelings like unworthiness. In spite of the internalisation process, this type of behavior is experienced as relatively controlled because individuals feel they must 
comply with partially internalised external standards that may conflict with their personal preferences (Ryan \& Deci, 2000a).

Second, SDT distinguishes two types of autonomous extrinsic motivation: identified and integrated regulation. These motivations are not only the product of an internalisation process in which individuals adopt external standards but also of an integration process in which individuals transform these standards to become an integral part of the self. When individuals accept and identify with the underlying value of a particular behavior, their motivational regulation is labeled identified (Ryan \& Deci, 2000a). For example, an employee who is motivated by identified regulation realises the importance of his work for his chosen career path. Since individuals experience some ownership of their behavior, this type of behavior is relatively autonomous. When the underlying value of a particular behavior is experienced as consistent with other important values and constitutes an integral part of the self, its regulation is integrated (Ryan \& Deci, 2000a). For example, an employee who is motivated by integrated regulation performs her job because it is completely in line with her core values. This type of behavior is truly autonomous because individuals experience their behavior as entirely volitional. Since behavior that is motivated by integrated regulation shares many characteristics with behavior that is motivated by intrinsic regulation (Ryan \& Deci, 2000a), integrated regulation is not examined separately here.

The social (or work) environment can facilitate or undermine internalisation and integration processes, intrinsic motivation, and personal growth by supporting or thwarting three innate psychological needs (Deci \& Ryan, 2000): the needs for relatedness, competence, and autonomy. The need for relatedness refers to the need for experiencing positive relationships with others and mutual respect, caring, and reliance (Baumeister \& Leary, 1995). The need for competence refers to the need for accomplishing challenging tasks successfully and obtaining desired results (White, 1959). Lastly, the need for autonomy refers to the need to experience freedom of choice and the opportunity to initiate behavior (Deci \& Ryan, 2000). Satisfaction of the three psychological needs, autonomous motivation, and the possibility of satisfying one's innate growth tendency are associated with optimal functioning and well-being. With respect to the work context, research has shown that satisfaction of psychological needs and autonomous motivation are associated with positive outcomes, such as task persistence, superior performance, job satisfaction, positive work attitudes, organisational commitment, and psychological well-being, whereas controlled motivation can detract from effective performance and well-being (Gagné \& Deci, 2005). Building upon this research, the present study explores the relationship between various types of motivational regulation and three different types of job-related well-being: workaholism, work engagement, and burnout.

(C) 2011 The Authors. Applied Psychology: An International Review (C) 2011 International Association of Applied Psychology. 


\section{The Present Study}

Workaholism has little to do with true love of one's work or with a genuine desire to contribute to organisational goals. Rather, workaholic employees work hard because they must do so: not working evokes distress and negative emotions such as irritability, anxiety, shame, and guilt. Apparently, workaholic employees try to avoid these negative feelings by throwing themselves into their work (Killinger, 2006). Furthermore, they have a higher need to prove themselves compared to non-workaholic employees. Therefore, it has been suggested that workaholism develops in response to feelings of low self-worth and insecurity (Mudrack, 2006). Ego involvement (Ryan, 1982), i.e. performing an activity in order to enhance or maintain self-esteem and self-worth, is prototypical for introjected regulation. In addition, workaholism is positively linked to socially prescribed perfectionism (Taris, Van Beek, \& Schaufeli, 2010), that is, people's beliefs that significant others hold high standards for them and that they only will be accepted if they meet these standards (Hewitt \& Flett, 1991). Socially prescribed perfectionism has been linked to controlled motivation, i.e. external regulation and introjected regulation (Miquelon, Vallerand, Grouzet, \& Cardinal, 2005). Accordingly, it can be assumed that the social environment plays an important role when it comes to workaholism, since it can provide workaholic employees with a sense of self-esteem and self-worth. For instance, workaholic employees are expected to be encouraged by status, peer admiration, and supervisor approval (Spence \& Robbins, 1992) and, based on research on self-esteem and self-efficacy, it is argued that workaholic employees pursue work that is likely to result in pay raises, promotions, or other signs of recognition (Porter, 1996). Recent findings confirm that satisfaction of the three innate psychological needs is negatively linked to working compulsively (Andreassen, Hetland, \& Pallesen, 2010), suggesting that for workaholic employees the freedom to be autonomously motivated is curtailed. Hence, it is expected that workaholism will be positively associated with controlled extrinsic motivation, i.e. external regulation and introjected regulation (Hypothesis 1).

Unlike workaholic employees, engaged employees work hard because they genuinely want to (Schaufeli \& Bakker, 2010). Since engaged employees experience high self-esteem, self-efficacy, and optimism, they are confident about their capabilities and optimistic about their future (Xanthopoulou, Bakker, Demerouti, \& Schaufeli, 2007). Individuals who evaluate themselves positively are less strongly affected by the social environment and by feedback (Brockner, 1988), and are likely to pursue goals that fit their ideals, interests, and values (Judge, Bono, Erez, \& Locke, 2005). Therefore, engaged employees will pursue self-concordant goals and engage in their work activities for autonomous reasons. In line with this notion, work engagement is 
associated with freedom in carrying out work activities and participating in work-related decisions (Schaufeli et al., 2008), indicating that engaged employees can often participate in activities that they value and find interesting. Not surprisingly, satisfaction of the three innate psychological needs has been positively linked to vigor and dedication, two key dimensions of engagement (Vansteenkiste, Neyrinck, Niemic, Soenens, De Witte, \& Van den Broeck, 2007). Need satisfaction is a requisite for the internalisation and integration of external standards as well as for intrinsic motivation. Thus, work engagement will be positively associated with autonomous motivation, i.e. identified regulation and intrinsic motivation (Hypothesis 2).

Finally, employees experiencing burnout have developed a mental distance from their work. They evaluate their performance negatively (Maslach, 1998), which may explain the low levels of performance-based and general self-esteem that are associated with burnout (Brookings, Bolton, Brown, \& McEvoy, 1985; Dahlin, Joneborg, \& Runeson, 2007). In addition, like workaholism, burnout is positively associated with socially prescribed perfectionism (Taris et al., 2010). Therefore, it is likely that employees with high scores on burnout work in order to obtain others' approval and to avoid additional negative effects on their self-evaluation. Moreover, employees experiencing burnout are cynical about their job, and no longer enjoy and derive satisfaction from their work (Maslach, 1998), suggesting that they are primarily motivated by controlled extrinsic motivation. Recent findings support these assumptions by showing that need satisfaction is negatively related to emotional exhaustion (Vansteenkiste et al., 2007). Unsatisfied needs obstruct the internalisation and integration of external standards as well as intrinsic motivation. Hence, burnout will be positively associated with controlled extrinsic motivation, i.e. external regulation and introjected regulation (Hypothesis 3).

Since work climate predicts need satisfaction and motivation (Gagné \& Deci, 2005) as well as job-related well-being (Schaufeli, Bakker, \& Van Rhenen, 2009b), the present study controls for work characteristics. Following the Job Demands-Resources (JD-R) model, we distinguish between job demands and job resources (Bakker \& Demerouti, 2008). Job demands are those aspects of work that require sustained physical and/or psychological effort or skills and that are associated with physiological and/or psychological costs. On the other hand, job resources are work aspects that are functional in achieving work goals, stimulate personal growth and development, and reduce job demands and the associated physiological and psychological costs. Based on previous research (e.g. Bakker \& Demerouti, 2007), three job demands (work overload, mental demands, and emotional demands) and three job resources (job control, social support from colleagues, and social support from supervisors) are examined in the present study. Figure 1 presents a heuristic research model that summarises the study hypotheses. In the 


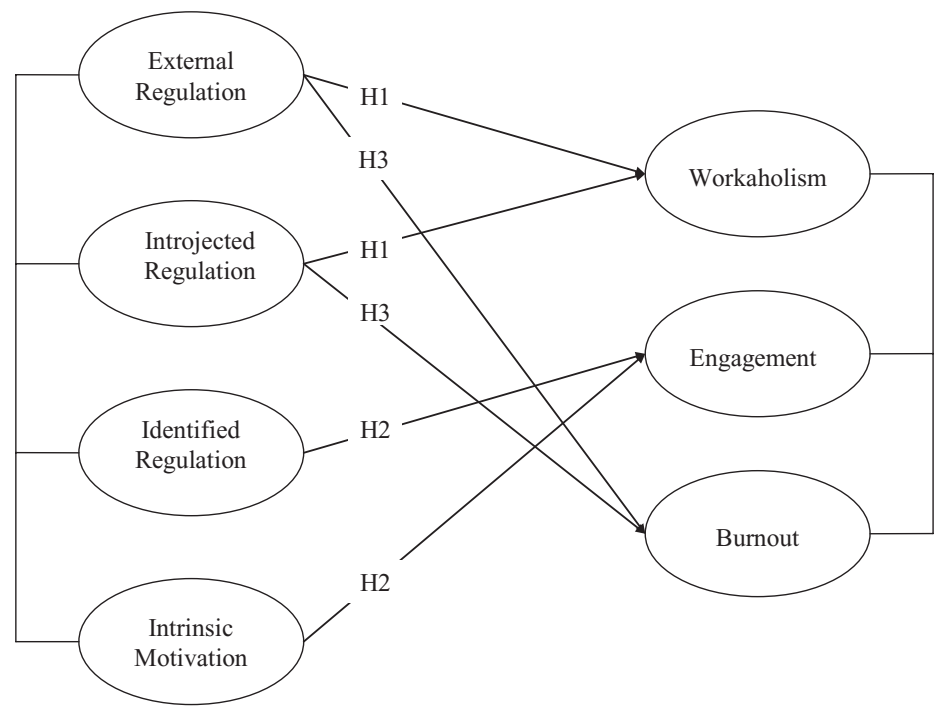

FIGURE 1. Heuristic model for the relations among various SDT-based types of motivation on the one hand, and workaholism, work engagement, and burnout on the other. In the analyses this model is extended with effects of job demands and job resources on the three well-being indicators.

analyses this model will be extended with the effects of job demands and job resources on all three measures of well-being.

\section{METHOD}

\section{Sample and Procedure}

One thousand questionnaires were randomly dispatched by a hospital administrator in four different types of hospitals (a general hospital, a maternity hospital, a traditional Chinese medicine hospital, and a psychiatric hospital) in an urban area in the mainland of China. The survey was accompanied by a letter explaining the nature and general aim of the study. After the data collection phase had expired, 760 usable questionnaires had been returned ( $76 \%$ response rate). The study sample included 544 nurses (538 females and six males, with a mean age of 29.23 years, $S D=7.48$ ) and 216 physicians (132 females and 84 males, with a mean age of 34.78 years, $S D=9.33$ ). The nurse sample worked on average 46.39 hours per week $(S D=7.40)$ and the physician sample worked on average 44.52 hours per week $(S D=8.07)$. Table 1 presents additional information on the sample. 
TABLE 1

Number of Questionnaires Dispatched, Return Rate (\%), and Number of Nurses and Physicians that Participated per Hospital

\begin{tabular}{lcccc}
\hline Type of hospital & Questionnaires dispatched & Return rate & Nurses & Physicians \\
\hline General hospital & 500 & 72.4 & 320 & 41 \\
Maternity hospital & 200 & 93 & 120 & 66 \\
Traditional Chinese & 230 & 68.7 & 72 & 86 \\
$\quad$ medicine hospital & 70 & 78.6 & 32 & 23 \\
Psychiatric hospital & 1,000 & 76 & 544 & 216 \\
Total & & & \\
\hline
\end{tabular}

\section{Instruments}

All study variables were measured with established scales that had been translated into Chinese by the second author and two native English teachers. Semantic vagueness was checked by two native Chinese teachers. Reliability analysis revealed that the internal consistencies (Cronbach's alphas) of all scales were acceptable $(\alpha>.70)$ to good $(\alpha>.80)$.

Workaholism was measured with the Dutch Work Addiction Scale (DUWAS; Schaufeli et al., 2009c). The DUWAS contains two subscales: Working Excessively and Working Compulsively. The first subscale is based on the Compulsive Tendencies scale of Robinson's (1999) Work Addiction Risk Test, whereas the second scale is based on the Drive scale of Spence and Robbins' (1992) Workaholism Battery. Working excessively was measured with nine items $(\alpha=.78)$, including "I seem to be in a hurry and racing against the clock". Working compulsively was measured with seven items $(\alpha=.77)$, including "I feel that there's something inside me that drives me to work hard". Items were scored on a 4-point frequency scale, ranging from 1 ("(almost) never") to 4 ("(almost) always").

Work engagement was measured with the Utrecht Work Engagement Scale (UWES; Schaufeli, Bakker, \& Salanova, 2006). The UWES consists of three subscales: Vigor, Dedication, and Absorption. Vigor was measured with three items $(\alpha=.82)$, including "At my work, I feel strong and vigorous". Dedication was measured with three items $(\alpha=.85)$, including "I am enthusiastic about my job". Finally, absorption was measured with three items $(\alpha=.84)$ as well, including "I am immersed in my work". All items employed a 7-point frequency scale, ranging from 0 ("never") to 6 ("always").

Burnout was measured with an adapted version of the Maslach Burnout Inventory-General Survey (MBI-GS; Schaufeli, Leiter, Maslach, \& Jackson, 1996). Two subscales were used: Emotional Exhaustion and Cynicism. Emotional exhaustion was measured with five items $(\alpha=.87)$, including "I feel burned out from my work". Cynicism was also measured with 
five items $(\alpha=.88)$, including "I doubt the significance of my work". All items were scored on a 7-point frequency scale, ranging from 0 ("never") to 6 ("always").

Motivation was measured with a 17 -item scale that was based on the scales of Ryan and Connell (1989) and Vansteenkiste, Sierens, Soenens, Luyckx, and Lens (2009). This scale contains four subscales: External Regulation, Introjected Regulation, Identified Regulation, and Intrinsic Motivation. External regulation was measured with four items $(\alpha=.88)$, including "I work to get the other's approval (e.g. supervisor, colleagues, family, clients)". Introjected regulation was measured using three items $(\alpha=.93)$, including "I work because otherwise I will feel bad about myself". Five items tapped identified regulation $(\alpha=.86)$, including "I work because what I do in this job has a lot of personal meaning to me". Lastly, five items tapped Intrinsic motivation $(\alpha=.94)$, including "I work because the work I do is a lot of fun". All items were scored on a scale that ranged from 1 ("totally disagree") to 5 ("totally agree").

Job demands were measured using items taken from three subscales of Van Veldhoven and Meijman's (1994) Dutch Questionnaire on the Experience and Evaluation of Work (VBBA). Work overload was measured with five items $(\alpha=.82)$, including "Do you have too much work to do?" Mental demands were also measured with five items $(\alpha=.82)$, including "Does your work require much concentration?" Emotional demands were measured with three items $(\alpha=.78)$, including "Does your work put you in emotionally upsetting situations?" Items were scored on a 5-point frequency scale, ranging from 1 ("never") to 5 ("always").

Finally, job resources were measured using items from three subscales developed by Van Veldhoven and Meijman (1994). Job control was measured using three items $(\alpha=.75)$, including "Do you have freedom in carrying out your work activities?" Social support from colleagues was measured with three items $(\alpha=.82)$, including "Can you count on your colleagues when you come across difficulties in your work?" Social support from supervisors was measured with three items as well $(\alpha=.79)$, including "If necessary, can you ask your direct manager for help?" All items were scored on a scale that ranged from 1 ("never") to 5 ("always").

\section{Statistical Analyses}

The research model presented in Figure 1 (Model 1, testing Hypotheses 1-3) was tested using Structural Equation Modeling methods as implemented in AMOS 16.0 (Arbuckle, 2007). Maximum likelihood estimation methods were used and the goodness-of-fit of the model was evaluated using the $\chi^{2}$ test statistic, the Goodness of Fit Index (GFI), the Normed Fit Index (NFI), the Tucker Lewis Index (TLI), and the Root Mean Square 
Error of Approximation (RMSEA). Values higher than .90 (for GFI, NFI, and TLI) or .08 or lower (for RMSEA) signify acceptable model fit (Byrne, 2009).

Preliminary Analyses. Preliminary confirmatory factor analyses were conducted on the pooled nurse and physician samples to test the hypothesised four-factor structure for the motivation scale. Results showed that a one-factor model, in which all items loaded on a single latent factor, did not fit the data well, $\chi^{2}=5,084.34$, GFI $=.50$, NFI $=.47$, TLI $=.40$, RMSEA $=.23$. Similarly, a two-factor model in which the items of external regulation and introjected regulation loaded on one latent factor (controlled motivation) and the items of identified regulation and intrinsic motivation loaded on a second latent factor (autonomous motivation) was rejected, $\chi^{2}=3,634.11, \mathrm{GFI}=.59, \mathrm{NFI}=.62, \mathrm{TLI}=.57, \mathrm{RMSEA}=.20$. In contrast, a four-factor model with items loading on the expected dimensions fit the data well, $\chi^{2}=359.36$, GFI $=.97, \mathrm{NFI}=.96, \mathrm{TLI}=.97$, RMSEA $=.05$, and significantly better than the one- and two-factor models, $\Delta \chi^{2}(N=760, d f=6)=4,724.98, p<.001$, and $\Delta \chi^{2}(N=760$, $d f=5)=3,274.75, p<.001$, respectively. Thus, these findings confirm the expectation that the motivation scale tapped four distinct regulatory styles.

Main Analyses. Three separate analyses tested whether the four dimensions of motivation were differentially related to workaholism, work engagement, and burnout, controlling for job demands and job resources. In Model 1a the effects of the four dimensions of motivation on workaholism were constrained to be equal (Hypothesis 1). In Model $1 \mathrm{~b}$ the effects of the four dimensions of motivation on work engagement were constrained to be equal (Hypothesis 2). Lastly, in Model 1c the effects of the four dimensions of motivation on burnout were constrained to be equal (Hypothesis 3). Comparison of the fit of Model 1 to that of Models 1a-1c would reveal whether the four dimensions of motivation are differentially associated with workaholism, work engagement, and burnout. For example, if the fit of Model 1a were significantly worse than that of Model 1, the four dimensions of motivation would relate differentially to workaholism. In these analyses the nurse and physician samples were pooled.

In the next step the invariance of the model across both samples was examined. Specifically, a two-group analysis tested whether Model 2, in which all paths were unconstrained, differed from Model 2a, in which all paths were constrained to be equal for the nurse and physician samples. A non-significant difference between the respective $\chi^{2}$ test statistics would indicate that Model 2 holds for the nurse and physician samples, while a signifi- 
cant difference would imply that Model 2 does not hold for both samples. If Model 2 differed for the nurse and physician samples, adaptations would be made so that a revised model emerged (Model 2b) that would be tested subsequently, etc. Finally, non-significant paths were to be removed, resulting in a final model (Model 3).

\section{RESULTS}

\section{Testing the Research Model}

Table 2 presents descriptive information for the study variables. In order to test the three hypotheses simultaneously, while controlling for the effects of job demands and job resources, the research model (Model 1, Figure 1) was fitted to the data. Table 3 shows that the goodness-of-fit indices of Model 1 were acceptable, meaning that it provided an acceptable starting point for further analysis. Constraining the effects of motivational regulation on workaholism in Model 1a, work engagement in Model 1b, and burnout in Model 1c resulted in significant deteriorations of the fit relative to Model 1, $\Delta \chi^{2}(N=760, d f=3)=21.1, p<.001 ; \Delta \chi^{2}(N=760, d f=3)=109.5, p<.001$; and $\Delta \chi^{2}(N=760, d f=3)=48, p<.001$, respectively. Thus, different types of motivational regulation related differentially to each of the three types of job-related well-being.

Next, a two-group analysis tested whether the research model held up for the nurse and physician samples. ${ }^{1}$ Table 3 shows that the unconstrained model (Model 2) fit the data significantly better than the constrained model (Model 2a), $\Delta \chi^{2}(N=760, d f=44)=78.2, p<.01$, indicating that the parameters of Model 2 differed across samples. Further inspection of Model 2a revealed that the nurse and physician samples differed regarding the relation between introjected regulation and burnout. For the physicians we observed a significant, positive association between introjected regulation and burnout, but not for the nurses. In Model $2 b$ all paths were constrained to be equal for both samples, with the exception of the path connecting introjected regulation and burnout. The $\chi^{2}$ test statistic differed significantly for Model 2 and Model 2b, $\Delta \chi^{2}(N=760, d f=43)=61.2, p<.05$, indicating that additional adaptations had to be made. Closer inspection showed that the nurse and physician samples differed regarding the relation between intrinsic motivation and workaholism as well: for the nurses we observed a significant, negative association between intrinsic motivation and workaholism, but not for the physicians. In Model 2c the path connecting intrinsic motivation and workaholism and the path connecting introjected

\footnotetext{
${ }^{1}$ Controlling for background variables (age and gender) did not affect the path coefficients of the models substantially.
}

(C) 2011 The Authors. Applied Psychology: An International Review (C) 2011 International Association of Applied Psychology. 


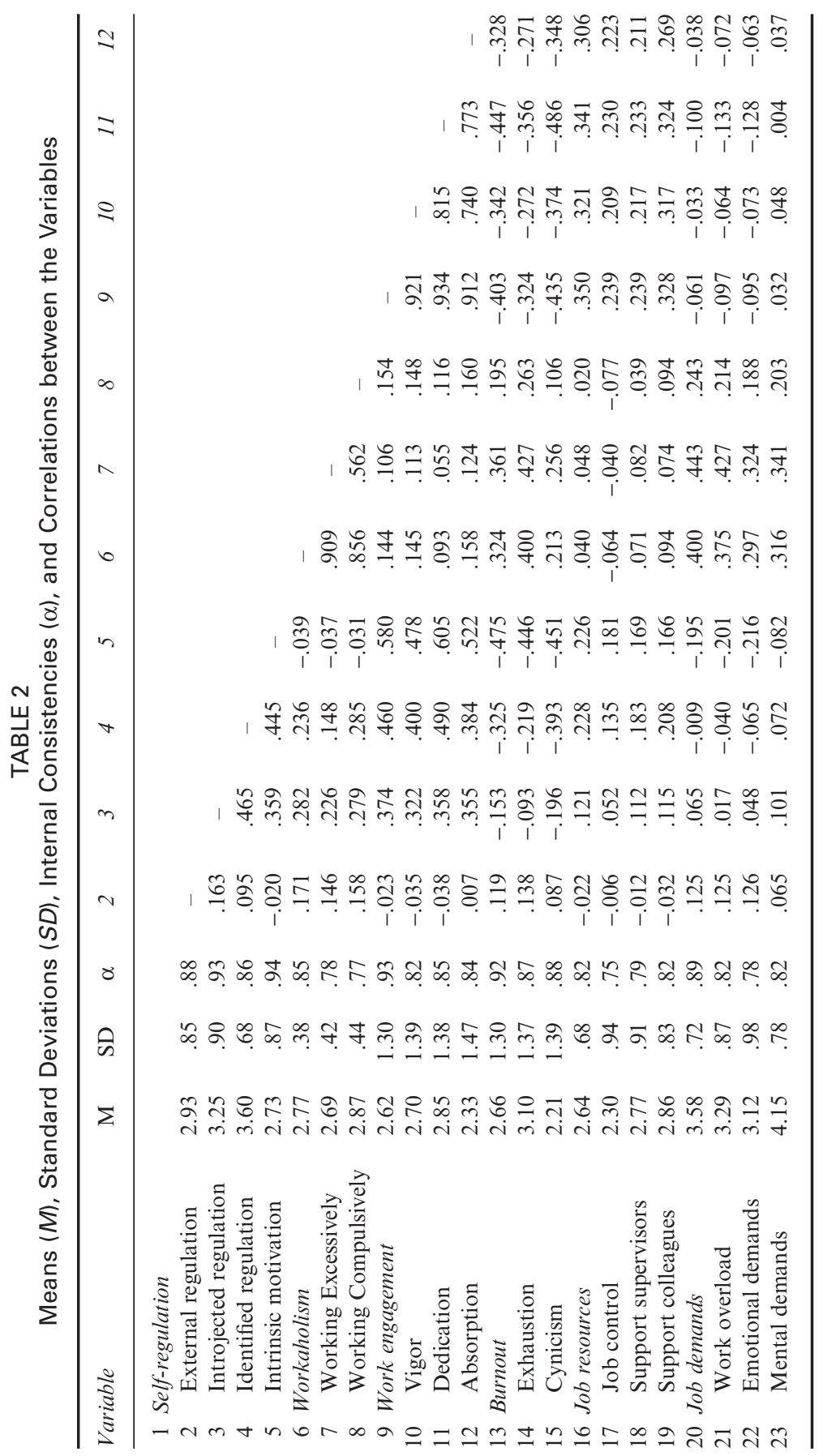

(C) 2011 The Authors. Applied Psychology: An International Review (C) 2011 International Association of Applied Psychology. 


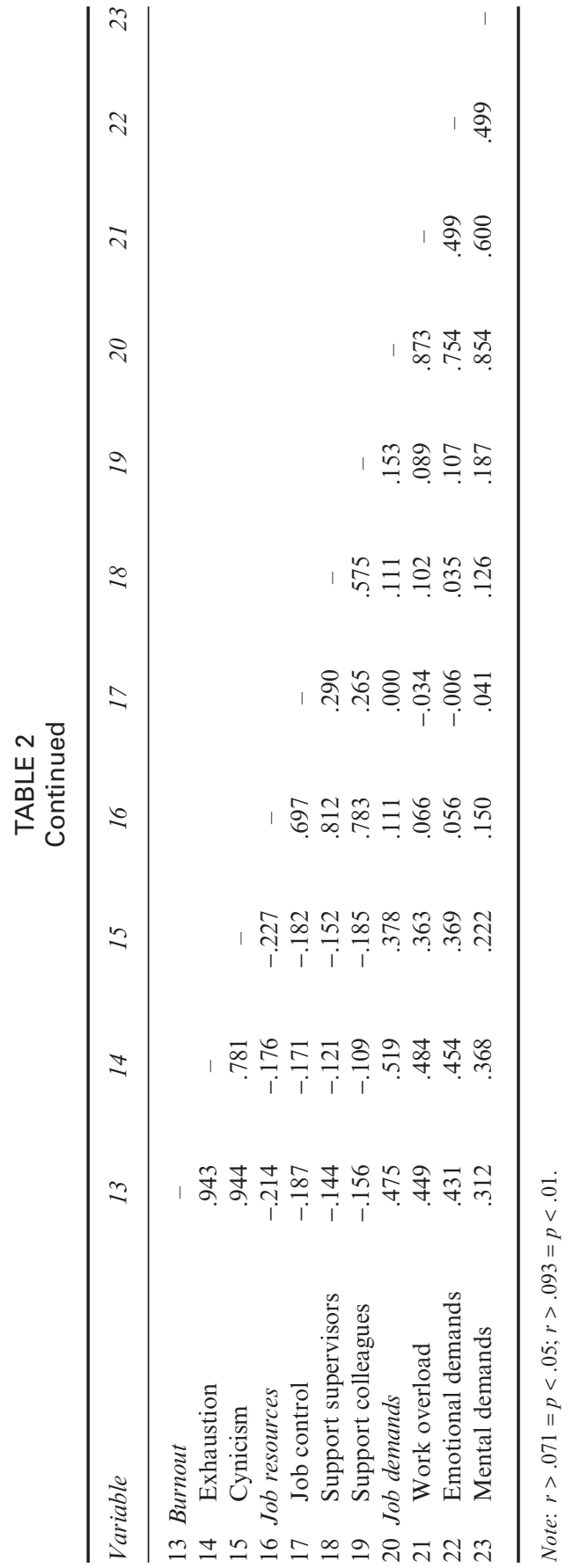

(C) 2011 The Authors. Applied Psychology: An International Review (C) 2011 International Association of Applied Psychology. 
TABLE 3

Goodness-of-Fit Indices, $N=760$

\begin{tabular}{|c|c|c|c|c|c|c|}
\hline Model & $\chi^{2}$ & $\mathrm{df}$ & $G F I$ & $R M S E A$ & $N F I$ & $T L 1$ \\
\hline Model 1 (see Figure 1) & 388.1 & 87 & .95 & .07 & .93 & .92 \\
\hline $\begin{array}{l}\text { Model la (paths from } \\
\text { motivation regulation to } \\
\text { workaholism constrained } \\
\text { to be equal) }\end{array}$ & $409.2^{*}$ & 90 & .94 & .07 & .93 & .91 \\
\hline $\begin{array}{l}\text { Model } 1 \mathrm{~b} \text { (paths from } \\
\text { motivation regulation to } \\
\text { engagement constrained } \\
\text { to be equal) }\end{array}$ & $497.6^{*}$ & 90 & .93 & .08 & .91 & .89 \\
\hline $\begin{array}{l}\text { Model 1c (paths from } \\
\text { motivation regulation to } \\
\text { burnout constrained to } \\
\text { be equal) }\end{array}$ & $436.1 *$ & 90 & .94 & .07 & .92 & .91 \\
\hline $\begin{array}{l}\text { Model } 2 \text { (all paths } \\
\text { unconstrained) }\end{array}$ & 512.3 & 174 & .93 & .05 & .91 & .90 \\
\hline $\begin{array}{l}\text { Model 2a (paths } \\
\text { constrained to be equal } \\
\text { for both groups) }\end{array}$ & $590.5^{* *}$ & 218 & .92 & .05 & .90 & .92 \\
\hline $\begin{array}{l}\text { Model } 2 \mathrm{~b} \text { (paths } \\
\text { constrained to be equal } \\
\text { for both groups with the } \\
\text { exception of the path } \\
\text { between introjected } \\
\text { regulation and burnout) }\end{array}$ & $573.5^{* *}$ & 217 & .92 & .05 & .90 & .92 \\
\hline $\begin{array}{l}\text { Model 2c (paths } \\
\text { constrained to be equal } \\
\text { for both groups with the } \\
\text { exception of the path } \\
\text { between introjected } \\
\text { regulation and burnout } \\
\text { and the path between } \\
\text { intrinsic motivation and } \\
\text { workaholism) }\end{array}$ & 567.4 & 216 & .93 & .05 & .91 & .92 \\
\hline $\begin{array}{l}\text { Model } 3 \text { (Model 2c: } \\
\text { significant paths only) }\end{array}$ & 576.4 & 221 & .93 & .05 & .91 & .91 \\
\hline
\end{tabular}

Note: * This model fits the data significantly worse than Model 1. ** This model fits the data significantly worse than Model 2.

regulation and burnout were estimated. The fit of Model 2 and Model 2c did not differ significantly, $\Delta \chi^{2}(N=760, d f=42)=55.1, p>.05$, indicating that Model 2c applies to both samples. Finally, all non-significant paths were removed, resulting in Model 3 that also met the criteria for acceptable fit. Figure 2 presents the effects of Model 3 graphically.

(C) 2011 The Authors. Applied Psychology: An International Review (C) 2011 International Association of Applied Psychology. 


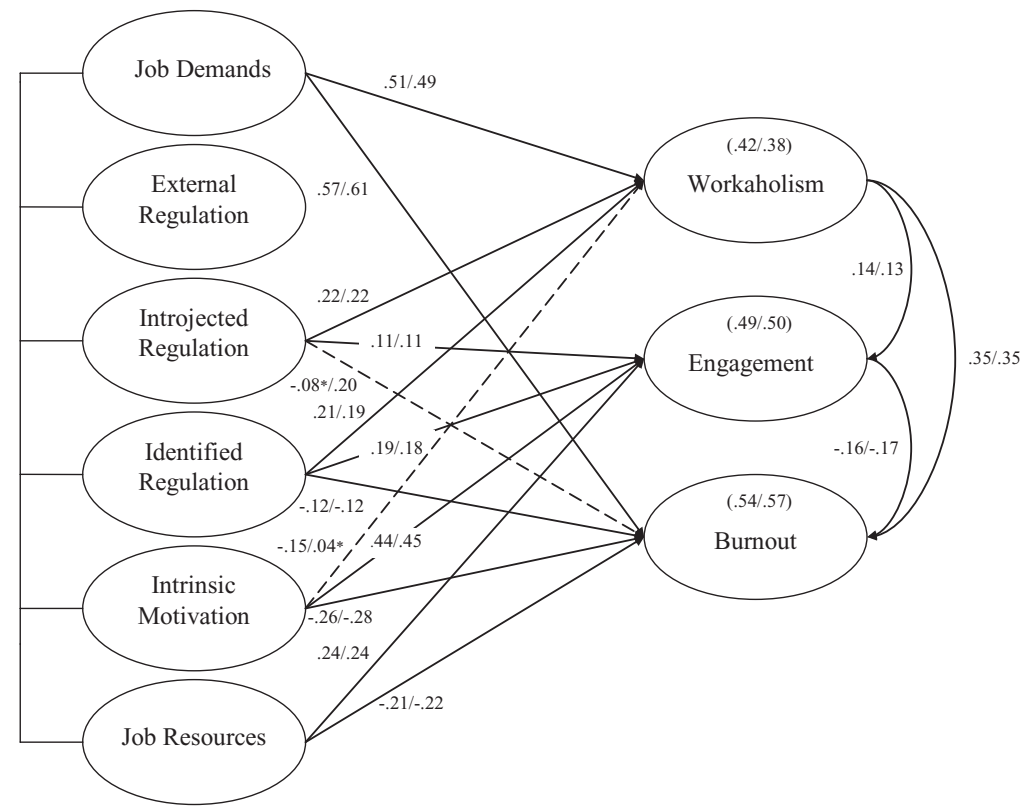

FIGURE 2. Model 3 with standardised path coefficients and squared multiple correlations for the nurse/physician sample.

Note: $* p \geq .05$.

\section{Testing the Hypotheses}

Workaholism and Motivational Regulation. Hypothesis 1 stated that workaholism would be positively associated with controlled extrinsic motivation (i.e. external regulation, introjected regulation). The findings displayed in Figure 2 partially confirmed this hypothesis. Workaholism was indeed positively related with introjected regulation, but not with external regulation. In addition, workaholism was positively linked to identified regulation for both the nurse and physician samples, and was negatively linked to intrinsic regulation for the nurse sample, but not for the physician sample.

Work Engagement and Motivational Regulation. Hypothesis 2 stated that work engagement would be positively associated with autonomous motivation, i.e. identified regulation and intrinsic motivation. Figure 2 shows that the obtained results confirmed this hypothesis. Work engagement was indeed positively related with identified regulation and intrinsic motivation. In addition, work engagement was positively linked to introjected regulation 
as well. All in all, the positive associations between work engagement and the different types of motivational regulation were stronger the more autonomous the motivation.

Burnout and Motivational Regulation. According to Hypothesis 3, burnout would be positively associated with controlled extrinsic motivation, i.e. external regulation and introjected regulation. As expected, burnout was positively related to introjected regulation for the physician sample, but not for the nurse sample (Hypothesis 3 partly supported). Moreover, burnout was negatively linked to autonomous motivation, i.e. identified regulation and intrinsic motivation.

Finally, note that we controlled for job demands and job resources that are known to influence both motivational regulation (Gagné \& Deci, 2005) and job-related well-being (Schaufeli et al., 2009a). Therefore, the associations among the various forms of motivational regulation and the three types of job-related well-being are independent from the perceived job demands and job resources.

\section{DISCUSSION}

The present study examined the motivational correlates of workaholism, work engagement, and burnout. Whereas previous research has identified a wide range of consequences of job-related well-being, their motivational antecedents have not been studied extensively. The present study revealed that Ryan and Deci's (2000a) Self-Determination Theory can fruitfully be used to study the motivational correlates of workaholism, work engagement, and burnout. Four interesting findings result from the present study.

First, workaholism is positively associated with extrinsic motivation, indicating that workaholic employees engage in their work activities for their instrumental value. Specifically, workaholism is positively associated with introjected regulation, meaning that workaholic employees have adopted external standards of self-worth and social approval without fully identifying with these standards. They buttress themselves with feelings of self-worth and self-esteem if they manage to meet these adopted external standards, but they feel ashamed, guilty, and unworthy when they fail to meet these standards (Deci \& Ryan, 2002). This is in line with the idea that workaholism develops in response to feelings of low self-worth and insecurity, and that workaholic employees are motivated by a high need to prove themselves (Mudrack, 2006). The present study does not support the idea that workaholic employees are motivated by external regulation, that is, external contingencies involving threats of punishments, or material or social rewards. This finding contradicts earlier suggestions that workaholic employees are encouraged by status, peer admiration, and supervisor approval (Spence \& Robbins, 1992),

(C) 2011 The Authors. Applied Psychology: An International Review (C) 2011 International Association of Applied Psychology. 
and that they pursue work that is likely to result in pay raises, promotions, or other signs of recognition (Porter, 1996). Importantly, these findings confirm the assumption that workaholic employees experience an inner compulsion to work hard rather than an external pressure. They work hard to avoid negative feelings, such as guilt and anxiety, or to attain ego enhancements, such as pride.

Furthermore, our findings revealed that workaholism is positively associated with identified regulation, indicating that some integration of adopted external standards has taken place and that the three innate psychological needs are at least to some extent fulfilled. Note that this finding contradicts recent findings that need satisfaction is negatively linked to working compulsively (Andreassen et al., 2010). Workaholic employees seem to value their work because they identify themselves with its instrumental value. Therefore, it is likely that workaholic employees experience some ownership of their behavior as well. This interesting finding may explain why they continue to work hard, despite the adverse consequences of doing so. In addition, workaholism is negatively associated with intrinsic motivation among nurses only, suggesting that workaholic nurses do not experience their work as interesting, enjoyable, or satisfying. This agrees with the observation that workaholism is negatively related with job satisfaction (Burke \& MacDermid, 1999). However, in the present study there was no relationship between workaholism and intrinsic motivation among physicians. It is possible that physicians are primarily motivated by their patients' requests for help and by the fact that their actions are often a matter of life or death. In general, these findings strengthen the interpretation that workaholic employees work so hard because it leads to a separable outcome (extrinsic motivation), and not because they like their job (intrinsic motivation).

Second, work engagement is positively associated with intrinsic motivation, indicating that engaged employees experience their work as interesting, enjoyable, and satisfying. These employees engage in their work for its own sake and act with a sense of volition. This may explain why engaged employees experience high levels of energy and mental resilience while working, are willing to invest effort in their work, are strongly involved in their work, and have difficulty detaching from work (Schaufeli et al., 2002). This finding is in line with previous findings that work engagement relates positively to job satisfaction and other positive outcomes, such as performance (Schaufeli \& Salanova, 2007a).

Third, work engagement is positively associated with extrinsic motivation, indicating that engaged employees engage in their work activities for their instrumental value as well. Specifically, work engagement is positively associated with introjected regulation and identified regulation. Like workaholic employees, engaged employees have apparently adopted external standards of self-worth and social approval without fully identifying with them 
(introjected regulation). Meeting these standards results in feelings of high self-worth and self-esteem, whereas failing to meet these standards leads to self-criticism and negative feelings (Deci \& Ryan, 2002). Therefore, engaged employees are likely to experience at least some internal pressure to work as well. In addition, our findings suggest that engaged employees identify themselves with the underlying value of their work (identified regulation). Since many jobs consist not only of interesting and enjoyable activities but also include mundane, repetitive, and unpleasant tasks, it makes sense that engaged employees are to some degree extrinsically motivated as well. The positive associations between work engagement and the different types of motivational regulation support the observation that engaged employees' innate psychological needs are for the greater part fulfilled (Vansteenkiste et al., 2007), because need satisfaction is a requisite for the internalisation and integration of external standards as well as for intrinsic motivation. Although the motivational make-up of work engagement is complex, engaged employees are mainly driven by autonomous motivation. They experience ownership of their behavior, meaning that they feel free to engage in activities that they personally value and that they enjoy for their own sake.

Fourth, burnout is negatively associated with intrinsic motivation and autonomous extrinsic motivation, indicating that burned-out employees do not experience their work activities as interesting, enjoyable, or satisfying, and do not identify with their work activities or their instrumental value. Since burnout refers to a state of exhaustion in which one is cynical about the value of one's own contribution at work (Maslach et al., 1996), these findings are not surprising. Furthermore, the present study shows that burnout is positively associated with introjected regulation for the physician group only. This suggests that, in contrast to nurses, burned-out physicians have adopted external standards of self-worth and social approval without fully identifying with them. One explanation for this finding is that physicians have a strong and internalised ethic of responsibility (Wu, Zhu, Li, Wang, \& Wang, 2008) that is, for instance, institutionalised in the Hippocratic Oath. As a result, physicians may feel they must work (i.e. work is a duty), whereas not working may induce negative feelings about oneself. This strong internalised work ethic may encourage the development of burnout, which could explain why physicians are among the occupational groups with the highest levels of burnout (Schaufeli, 2007). These findings support earlier findings that need satisfaction is negatively related to emotional exhaustion (Vansteenkiste et al., 2007). Unsatisfied needs obstruct the internalisation and integration of external standards as well as intrinsic motivation. Whereas burned-out physicians are primarily driven by introjected regulation, burned-out nurses are not driven by any of the motivational regulations in particular. These findings contradict the assumption that burned-out employees' behavior is motivated by both external and introjected regulation. Rather, these findings 
suggest that nurses experiencing burnout are a-motivated. A-motivation manifests itself by acting without intent or refraining from any acting. It is the consequence of not valuing an activity, not feeling competent to perform it, or not believing that it will lead to a desired outcome (Ryan \& Deci, 2000a). It seems plausible that burned-out employees are a-motivated because they distance themselves from their work to prevent further depletion of mental resources.

\section{Study Limitations}

One limitation of the present study is that all constructs were measured using self-reports, which may have inflated the associations among the study variables due to common method variance or the wish to answer consistently. However, Spector (2006) argued convincingly that self-reports do not automatically and inevitably inflate associations between variables and do not necessarily lead to significant results, even in large samples. Moreover, the associations reported in Table 2 show considerable variation, which goes against the idea that these are due to a common underlying process that affects all these correlations uniformly.

Second, our data were collected among a relatively homogeneous sample of Chinese medical professionals. Although these professionals worked at four different hospitals (providing a broad impression of the working circumstances across various types of hospitals), all of these were located in the same medium-sized city in China. Therefore, it cannot be claimed that the sample is representative of the full medical sector in China. In addition, at present it is too early to generalise the findings to other occupations or cultures. On the other hand, virtually all studies using SDT as theoretical framework have been carried out in Western countries. In this sense the fact that this study was conducted in China is also a strength, as it underlines the cross-cultural validity of SDT. Moreover, the findings presented here are largely in line with our expectations, suggesting that the findings of the present study could well apply to other occupational groups and to less collectivistic cultures.

Third, the present study used a cross-sectional design. Consequently, it cannot be concluded that specific types of motivational regulation lead causally to specific types of employee well-being. In addition, there are indications that workaholism, work engagement, and burnout are causally linked. However, the cross-sectional design did not allow us to examine the causal relations among these concepts. For instance, workaholism may act as a root cause of burnout, since workaholic employees may deplete their mental resources (Porter, 2001). Furthermore, Schaufeli, Taris, Le Blanc, Peeters, Bakker, and De Jonge (2001) showed that burned-out employees may initially have been engaged and vice versa. Solid evidence for such causal 
relations is still lacking. Therefore, the present study treated workaholism, work engagement, and burnout as correlates. Because alternative (reversed or reciprocal) causal relations between motivational regulation and job-related well-being cannot be excluded and possible causal relations among the three different kinds of job-related well-being are an interesting issue, it would be worthwhile replicating the present study longitudinally.

\section{Theoretical and Practical Implications}

The present study extends previous research in at least three ways. First, it is the first to uncover the motivational correlates of workaholism, work engagement, and burnout using SDT and to show that these correlates differ substantially and meaningfully. However, the motivational correlates of these three kinds of job-related well-being are more complex than was initially assumed. Although workaholic employees are basically extrinsically motivated, engaged employees are both extrinsically and intrinsically motivated. Hence, workaholism and work engagement overlap partly in terms of their motivational regulation. This is plausible in that work consists of interesting and enjoyable activities as well as mundane and unpleasant tasks. This finding should therefore not be interpreted as evidence for a conceptual overlap of these concepts; even if two phenomena (e.g. lung cancer and cardiac complaints) share the same antecedent (smoking), it does not follow that they are conceptually similar. Moreover, the correlations between workaholism and work engagement were small, $r$ s were .14 for nurses and .13 for physicians, indicating that these concepts share less than 2 per cent of their variance. Based on the present study, a prototypical distinction can be made regarding the motivation of workaholic and engaged employees: Workaholic employees are mainly extrinsically motivated and engage in job activities for their instrumental value, while engaged employees are mainly intrinsicically motivated and experience their work as inherently enjoyable and satisfying.

Second, the present study provides indirect evidence for SDT's assumption that human beings are active, growth-oriented organisms and that fostering this tendency leads to optimal functioning and well-being, whereas thwarting it leads to adverse outcomes. The present study showed that work engagement varied positively with the degree to which one's work behavior is autonomously motivated and, thus, with the degree to which one's innate growth tendency is realised. Conversely, being internally pressured to work is associated with higher levels of workaholism and burnout.

Third, the present study provides directions for practical use. Since work engagement is linked to beneficial outcomes at the individual and organisational levels (Schaufeli \& Salanova, 2007a; Schaufeli et al., 2008), companies are advised to stimulate this type of job-related well-being. In contrast, because workaholism and burnout are mainly linked to adverse outcomes

(C) 2011 The Authors. Applied Psychology: An International Review (C) 2011 International Association of Applied Psychology. 
(Burke, 2000; Maslach et al., 2001; Schaufeli et al., 2009a), companies should avoid these psychological states in their employees. The present study suggests that fostering autonomous motivation may simultaneously lead to an increase in work engagement and a decrease in workaholism and burnout. One way to achieve this is by making jobs more attractive and challenging to employees, and adopting an autonomy-supportive management style that includes being emphatic, offering choices, and providing meaningful rationales for doing particular tasks (Gagné \& Deci, 2005).

\section{Concluding Comment}

The present study examined the motivational correlates of workaholism, work engagement, and burnout. Workaholic employees work hard because they are mainly driven or pushed by a strong need to prove themselves and because they personally value work outcomes, while engaged employees work hard because they are mainly pulled by their inherently enjoyable and satisfying work. Finally, employees experiencing burnout are neither pushed nor pulled to work; rather, they distance themselves from their work. Although the associations among motivational regulation and job-related well-being are more complex than was anticipated, the present study demonstrated that workaholism, work engagement, and burnout are each associated with a prototypical underlying motivational regulation.

\section{REFERENCES}

Andreassen, C.S., Hetland, J., \& Pallesen, S. (2010). The relationship between workaholism, basic needs satisfaction at work and personality. European Journal of Personality, 24, 3-17.

Arbuckle, J.L. (2007). AMOS 16.0 (Computer Software). Chicago, IL: SPSS Inc.

Bakker, A.B., \& Demerouti, E. (2007). The Job Demands-Resources model: State of the art. Journal of Managerial Psychology, 22, 309-328.

Bakker, A.B., \& Demerouti, E. (2008). Towards a model of work engagement. Career Development International, 13, 209-223.

Baumeister, R., \& Leary, M.R. (1995). The need to belong: Desire for interpersonal attachments as a fundamental human motivation. Psychological Bulletin, 177, 497-529.

Bonebright, C.A., Clay, D.L., \& Ankenmann, R.D. (2000). The relationship of workaholism with work-life conflict, life satisfaction, and purpose in life. Journal of Counseling Psychology, 47, 469-477.

Brockner, J. (1988). The effects of work layoffs on survivors: Research, theory, and practice. In B.M. Staw \& L.L. Cummings (Eds.), Research in organizational behavior (Vol. 10, pp. 213-255). Greenwich, CT: JAI Press.

Brookings, J.B., Bolton, B., Brown, C.E., \& McEvoy, A. (1985). Self-reported job burnout among female human service professionals. Journal of Occupational Behavior, 6, 143-150. 
Burke, R.J. (2000). Workaholism in organizations: Psychological and physical wellbeing consequences. Stress Medicine, 16, 11-16.

Burke, R.J., \& MacDermid, G. (1999). Are workaholics job satisfied and successful in their careers? Career Development International, 4, 277-282.

Byrne, B.M. (2009). Structural equation modeling with AMOS: Basic concepts, programming, and applications (2nd edn.). Mahwah, NJ: Erlbaum.

Dahlin, M., Joneborg, N., \& Runeson, B. (2007). Performance-based self-esteem and burnout in a cross-sectional study of medical students. Medical Teacher, 29, 43-48.

Deci, E.L., \& Ryan, R.M. (1985). Intrinsic motivation and self-determination in human behavior. New York: Plenum.

Deci, E.L., \& Ryan, R.M. (2000). The "what" and "why" of goal pursuits: Human needs and the self-determination of behavior. Psychological Inquiry, 11, 227-268.

Deci, E.L., \& Ryan, R.M. (2002). An overview of self-determination theory. In E.L. Deci \& R.M. Ryan (Eds.), Handbook of self-determination research (pp. 3-33). Rochester, NY: University of Rochester Press.

Frese, M. (2008). The changing nature of work. In N. Chmiel (Ed.), An introduction to work and organizational psychology (pp. 397-414). Oxford: Blackwell.

Gagné, M., \& Deci, E. (2005). Self-determination theory and work motivation. Journal of Organizational Behavior, 26, 331-362.

Hewitt, P.L., \& Flett, G.L. (1991). Perfectionism in the self and social contexts: Conceptualization, assessment, and association with psycho-pathology. Journal of Personality and Social Psychology, 60, 456-470.

Judge, T.A., Bono, J.E., Erez, A., \& Locke, E.A. (2005). Core self-evaluations and job and life satisfaction: The role of self-concordance and goal attainment. Journal of Applied Psychology, 90, 257-268.

Killinger, B. (2006). The workaholic breakdown syndrome. In R. Burke (Ed.), Research companion to working time and work addiction (pp. 61-88). Cheltenham: Edward Elgar.

Koestner, R., \& Losier, G.F. (2002). Distinguishing three ways of being highly motivated: A closer look at introjection, identification, and intrinsic motivation. In E.L. Deci \& R.M. Ryan (Eds.), Handbook of self-determination research (pp. 101-122). Rochester, NY: University of Rochester Press.

McMillan, L.H.W., \& O'Driscoll, M.P. (2004). Workaholism and health: Implications for organizations. Journal of Organizational Change Management, 17, 509519 .

McMillan, L.H.W., \& O’Driscoll, M.P. (2006). Exploring new frontiers to generate an integrated definition of workaholism. In R. Burke (Ed.), Research companion to working time and work addiction (pp. 89-107). Cheltenham: Edward Elgar.

Maslach, C. (1998). A multidimensional theory of burnout. In C.L. Cooper (Ed.), Theories of organizational stress (pp. 68-85). Oxford: Oxford University Press.

Maslach, C., Jackson, S.E., \& Leiter, M.P. (1996). MBI: The Maslach Burnout Inventory: Manual. Palo Alto, CA: Consulting Psychologists Press.

Maslach, C., Schaufeli, W.B., \& Leiter, M.P. (2001). Job burnout. Annual Review of Psychology, 52, 397-422.

(C) 2011 The Authors. Applied Psychology: An International Review (C) 2011 International Association of Applied Psychology. 
Miquelon, P., Vallerand, R.J., Grouzet, F.M.E., \& Cardinal, G. (2005). Perfectionism, academic motivation, and psychological adjustment: An integrative model. Personality and Social Psychology Bulletin, 31, 913-924.

Mudrack, P.E. (2006). Understanding workaholism: The case of behavioral tendencies. In R.J. Burke (Ed.), Research companion to working time and work addiction (pp. 108-128). Cheltenham: Edward Elgar.

Porter, G. (1996). Organizational impact of workaholism: Suggestions for researching the negative outcomes of excessive work. Journal of Occupational Health Psychology, $1,70-84$.

Porter, G. (2001). Workaholic tendencies and the high potential for stress among co-workers. International Journal of Stress Management, 8, 147-164.

Robinson, B.E. (1999). The Work Addiction Risk Test: Development of a tentative measure of workaholism. Perceptual and Motor Skills, 88, 199-210.

Ryan, R.M. (1982). Control and information in the intrapersonal sphere: An extension of cognitive evaluation theory. Journal of Personality and Social Psychology, $43,450-461$.

Ryan, R.M., \& Connell, J.P. (1989). Perceived locus of causality and internalization: Examining reasons for acting in two domains. Journal of Personality and Social Psychology, 57, 749-761.

Ryan, R.M., \& Deci, E.L. (2000a). Self-determination theory and the facilitation of intrinsic motivation, social development, and well-being. American Psychologist, $55,68-78$.

Ryan, R.M., \& Deci, E.L. (2000b). Intrinsic and extrinsic motivation: Classic definitions and new directions. Contemporary Educational Psychology, 25, 6878.

Salanova, M., Agut, S., \& Peiró, J.M. (2005). Linking organizational resources and work engagement to employee performance and customer loyalty: The mediation of service climate. Journal of Applied Psychology, 90, 1217-1227.

Salanova, M., \& Schaufeli, W.B. (2008). A cross-national study of work engagement as a mediator between job resources and proactive behaviour. International Journal of Human Resource Management, 19, 116-131.

Schaufeli, W.B. (2007). Burnout in health care. In P. Carayon (Ed.), Handbook of human factors and ergonomics in health care and patient safety (pp. 217-232). Mahwah, NJ: Lawrence Erlbaum.

Schaufeli, W.B., \& Bakker, A.B. (2010). The conceptualization and measurement of work engagement. In A.B. Bakker \& M.P. Leiter (Eds.), Work engagement: A handbook of essential theory and research. New York: Routledge.

Schaufeli, W.B., Bakker, A.B., \& Salanova, M. (2006). The measurement of work engagement with a short questionnaire: A cross-national study. Educational and Psychological Measurement, 66, 701-716.

Schaufeli, W.B., Bakker, A.B., Van der Heijden, F.M.M.A., \& Prins, J.T. (2009a). Workaholism, burnout and well-being among junior doctors: The mediating role of role conflict. Work \& Stress, 23, 155-172.

Schaufeli, W.B., Bakker, A.B., \& Van Rhenen, W. (2009b). How changes in job demands and resources predict burnout, work engagement, and sickness absenteeism. Journal of Organizational Behavior, 30, 893-917. 
Schaufeli, W.B., Leiter, M.P., Maslach, C., \& Jackson, S.E. (1996). Maslach Burnout Inventory-General Survey. In C. Maslach, S.E. Jackson, \& M.P. Leiter (Eds.), The Maslach Burnout Inventory: Test manual (3rd edn., pp. 22-26). Palo Alto, CA: Consulting Psychologists Press.

Schaufeli, W.B., \& Salanova, M. (2007a). Work engagement: An emerging psychological concept and its implications for organizations. In S.W. Gilliland, D.D. Steiner, \& D.P. Skarlicki (Eds.), Research in social issues in management (Vol. 5; pp. 135-177). Greenwich, CT: Information Age Publishers.

Schaufeli, W.B., \& Salanova, M. (2007b). Efficacy or inefficacy, that's the question: Burnout and work engagement, and their relationship with efficacy beliefs. Anxiety, Stress \& Coping, 20, 177-196.

Schaufeli, W.B., Salanova, M., Gonzalez-Romá, V., \& Bakker, A.B. (2002). The measurement of engagement and burnout: A two sample confirmatory factor analytic approach. Journal of Happiness Studies, 3, 71-92.

Schaufeli, W.B., Shimazu, A., \& Taris, T.W. (2009c). Being driven to work exceptionally hard: The evaluation of a two-factor measure of workaholism in the Netherlands and Japan. Cross-Cultural Research, 43, 320-348.

Schaufeli, W.B., Taris, T., Le Blanc, P., Peeters, M., Bakker, A., \& De Jonge, J. (2001). Maakt arbeid gezond? Op zoek naar de bevlogen werknemer [Can work produce health? The quest for the engaged worker]. De Psycholoog, 36, 422428.

Schaufeli, W.B., Taris, T.W., \& Van Rhenen, W. (2008). Workaholism, burnout, and engagement: Three of a kind or three different kinds of employee well-being? Applied Psychology: An International Review, 57, 173-203.

Scott, K.S., Moore, K.S., \& Miceli, M.P. (1997). An exploration of the meaning and consequences of workaholism. Human Relations, 50, 287-314.

Shimazu, A., \& Schaufeli, W.B. (2009). Is workaholism good or bad for employee well-being? The distinctiveness of workaholism and work engagement among Japanese employees. Industrial Health, 47, 495-502.

Shirom, A., Melamed, S., Toker, S., Berliner, S., \& Shapira, I. (2005). Burnout, mental and physical health: A review of the evidence and a proposed explanatory model. International Review of Industrial and Organizational Psychology, 20, 269309.

Sonnentag, S. (2003). Recovery, work engagement, and proactive behavior: A new look at the interface between nonwork and work. Journal of Applied Psychology, $88,518-528$.

Spector, P.E. (2006). Method variance in organizational research: Truth or urban legend? Organizational Research Methods, 9, 221-232.

Spence, J.T., \& Robbins, A.S. (1992). Workaholism: Definition, measurement, and preliminary results. Journal of Personality Assessment, 58, 160-178.

Taris, T.W., Schaufeli, W.B., \& Verhoeven, L.C. (2005). Workaholism in the Netherlands: Implications for job strain and work-nonwork conflict. Applied Psychology: An International Review, 54, 37-60.

Taris, T.W., Van Beek, I., \& Schaufeli, W.B. (2010). Why do perfectionists have a higher burnout risk than others? A mediational analysis. Romanian Journal of Applied Psychology, 12, 1-7. 
Van Veldhoven, M., \& Meijman, T.F. (1994). Het meten van psychosociale arbeidsbelasting met een vragenlijst: De Vragenlijst Beleving en Beoordeling van de Arbeid [The measurement of psychosocial strain at work: The questionnaire experience and evaluation of work]. Amsterdam: NIA.

Vansteenkiste, M., Neyrinck, B., Niemic, C., Soenens, B., De Witte, H., \& Van den Broeck, A. (2007). Examining the relations among extrinsic versus intrinsic work value orientations, basic need satisfaction, and job experiences: A SelfDetermination Theory approach. Journal of Occupational and Organizational Psychology, 80, 251-277.

Vansteenkiste, M., Sierens, E., Soenens, B., Luyckx, K., \& Lens, W. (2009). Motivational profiles from a self-determination perspective: The quality of motivation matters. Journal of Educational Psychology, 101, 671-688.

White, R.W. (1959). Motivation reconsidered. Psychological Review, 66, 297-333.

Wu, S., Zhu, W., Li, H., Wang, Z., \& Wang, M. (2008). Relationship between job burnout and occupational stress among doctors in China. Stress and Health, 24, 143-149.

Xanthopoulou, D., Bakker, A.B., Demerouti, E., \& Schaufeli, W.B. (2007). The role of personal resources in the Job Demands-Resources model. International Journal of Stress Management, 14, 121-141. 